\title{
Therapeutic Interventions and Their Benefits in the Autism Spectrum Disorder
}

\author{
José Antônio Da Silva Neto, Ana Carolina de Holanda Machado, Deborah Gerrane Damásio \\ Nascimento, Mariana Ribeiro Rodrigues Alves, Vitória Daiany Guimarães Ramos and Andréia \\ Moreira da Silva Santos
}

Centro Universitário UniEvangélica de Anápolis-Goiás, Brazil

*Corresponding author: José Antônio da Silva Neto, Centro Universitário UniEvangélica de Anápolis-Goiás, Brazil

\section{ARTICLE INFO}

Received: May 14, 2020

Published: 幽 May 20, 2020

Citation: José Antônio Da SN, Ana Carolina de HM, Deborah Gerrane DN, Mariana Ribeiro RA, Vitória Daiany GR, Andréia Moreira da SS. Therapeutic Interventions and Their Benefits in the Autism Spectrum Disorder. Biomed J Sci \& Tech Res 27(5)2020. BJSTR. MS.ID.004555.

\section{Abstract}

Autism Spectrum Disorder (ASD) is defined as a complex disorder of the neurological system, characterized for social behavior and communication impairment. This review analyzed twenty-one clinical trials that address different kind of therapies. Interventional therapies for children with ASD are multiple, and achieve diverse behavioral, psychosomatic aspects and general improvement skills. However, the therapy effectiveness is substantially related to the family engagement, and mainly to the connection that the individual with ASD has with it.

Keywords: Autism Spectrum Disorder; Therapy; Children

\section{Mini Review}

Autism is defined as a complex disorder of the neurological system, characterized for social behavior and communication impairment. In addition to a strict repertoire of interests and activities. The spectrum reflects levels of autism (high functional autism to severe autism) and how it would affect the individual behavior [1]. Otherwise, etymologically, autism is defined as an act of orientation from each own prospect, someone closed in himself [2].The growth rate of children diagnosed with Autism Spectrum Disorder (ASD) is getting higher, in The United States of America, for example the rate is 1:59 [3]. Then, the existing interventions are multiple and diverse, and it is applied according to the compliance that the children with ASD presents. The therapies can address multifactorial, behavioral, or cognitive aspects. However, because of the lengthy waitlists, not all diagnosed autistic receives early treatment [3]. Garcia-Villamisar; Dattilo and Muela (2017) [4] have shown some facing difficulties that children with ASD are compromised, such as: bullying; restricted labor market; few interpersonal connections; lack of group interactions. To overcome these intricacies the adult therapeutic recreation, highlighting the differences and social needs of children with ASD need to be addressed. The importance of multidisciplinary therapies to achieve a better life quality is undoubted. The objective of this mini review is to present the therapeutic interventions for children with ASD.

\section{Methods}

This review analyzed twenty-one clinical trials that address different kind of therapies (used in many therapeutic method forms, such as Applied Behavioral analysis-ABA or Denver model) for the improvement of social skills for the autistic children. From that, these therapies were cataloged in five (5) categories: therapies using informational technologies; with family participation; with animal interaction; in autistic groups; and behavior-cognitive or non-specified therapies. Then, these interventions are fundamental for the developmental of general life skills for the autistic people, whereas they have shorter life quality than neurotypics [4].

\section{Therapies Using Informational Technologies}

Use of informational technologies are considered complementary to the major therapy, as ABA (Applied Behavior Analysis) or Enhanced Standard Care [3]. However, besides these therapies are considered complementary, they collaborate to the improvement of the following aspects in the autism spectrum: 
facial engagement; recognition of facial expressions; social responsiveness; cognitive aspects; personal well-being; social skills; imitation skills; receptive language; planning skills and selfconfidence [4-9]. Two clinical trials using the mobile app TOBY (Therapy Outcomes by You) have shown that the app can improve mainly the aspect of language receptiveness, however, it was noticed that it depends on the family engagement and adherence of the children with ASD $[5,6]$.

\section{Therapies With Family Participation}

The significance of the family training for the full monitoring of their autistic children has been a concern in last few years. Dawalt; [10] Greenberg; Mailick (2018) applied the family training called: Transitioning together, for the transitioning adaptation for the adulthood, it was noticed the improvement of parent-children relationship, resulting in a better tolerance; well-being, both from the parents and the child prospects; social commitment and reduction of the parent stress and depression. Zhou et al (2017) [11] based in the Early Start Denver Model Intervention (ESDN), which consists of increasing playful activities in the family routine, showed positive outcomes in aspects such as: prolonged eye contact; name response; social responsiveness; pointing to objects. However, it did not showed improvement in imitating skills. Therefore, the effectiveness of ESDN method demonstrates positive outcomes in several aspects, both for the family nucleus and its children with ASD.

Lack of qualified professionals; long waiting lists; financial limits; transportation limits; lack of health infant care; geographic isolations and time limitations are some difficulties faced by families of children with ASD. Ingersoll et al. (2016) [12] have shown that Therapist-Assisted Telehealth Parent-Mediated Intervention could be a good model to use to diminish these difficulties, they reported that stress is decreased in comparison to the presential therapy and language and social skills are increased.

\section{Therapies With Animal Interaction}

In a Hungarian clinical trial [13] which had the purpose of a medical explanation in the infant gait cycle and in the development of mental skills in children with ASD, the therapeutic horse riding was applied as a therapeutic method. In this study the two (2) formed groups had both pedagogical education sessions, but only one (1) received sessions of therapeutic horse riding during thirty minutes per week. Thus, the therapeutic horse riding showed improvement in mental skills and motor coordination. Although, this kind of intervention is characterized as an alternative therapy, or a kind of rehabilitation, in cases that other types of intervention are not effective[13].

\section{Group Therapy for ASD}

The therapies based in interventions in group therapy evidenced improvement in each following areas: social interaction for both autistic teenagers and children; communication skills; development of social motivation; progress in self-awareness and others; increase of the capacity of problem resolution; selfconfidence; comprehension of the performed therapy; and increase of group engagement to the therapy. Although, this type of intervention showed effectiveness, to achieve these benefits, it must be a long-term therapy [14,15]. The study of Begeer et al. (2015) [15] used diverse activities to be performed for each group, this activities were based in improvement of Teory of Mind (ToM)Effects and Moderators of a Short Theory of Mind Intervention - which is a central deficit of ASD. The sessions and exercises performed were capable to develop conceptual-behaviorist social comprehension related to ToM in the autistic group. However, the major goal to improve logic to emotions or advanced problems could not be achieved, because the limitations of the method.

\section{Behavioral-Cognitive or Non-Specified Therapies}

The interventions catalogued in this type are multiple kinds, and aim diverse improvements, however, not all kinds have the behaviorist psychological orientation, which is the case of the somatosensory therapy. This type of intervention looks for the decrease of pain sensitivity and abnormal tactile stimuli responses. They conclude that the decrease of such dysfunctions is related to the decrease of self-injuring actions, reduced sleeps and increase of integration [16]. Bieleninik et al. (2017) [17] compared in nine countries the methods of improvisational music therapy and enhanced standard care (which is defined as multiple interventions available in each location, in addiction to parent orientation). It was concluded that between the two forms of interventions, there is no significant difference in the improvement of the autistic characteristics based in the domain of social affection scales. Although, these two forms of intervention are proved to be effective [17]. Interventions related to environmental enrichment had been used to apply diverse exercises to promote the development olfactory, tactile, thermal, auditory, visual senses and engine systems in children with ASD.

These exercises had been showed statistically significant improvement in the QI scores, a decrease in atypical sensorial responses, and development of receptive language [18]. Other behavioral-cognitive therapy has been showed improvement of the anxiety in children with ASD. Van Steensel et al. (2016) [19] showed that the conquered earnings during the interventions were kept even after the end of the research, besides that this same intervention used in ASD was used as therapy in cases of anxiety disorders. On the other hand, the Vroland-Norstrand et al. (2017) [20] study have noticed that children with ASD are capable of contribute with a personal prospect about what is or not important for them, with that, objectives are reached as they achieve goals together with colleagues. The intervention was performed in the presence of occupational therapists and parents. The conclusion was an evolution in the integration with colleagues in leisure activities and in the school $[21,22]$. 


\section{Conclusion}

Therefore, the interventional therapies for children with ASD are multiple, and achieve diverse behavioral, psychosomatic aspects and general improvement skills. However, the therapy effectiveness is substantially related to the family engagement, and, mainly, to the connection that the individual with ASD has with it. Then, it is extremely necessary an increase in research that investigate the efficacy and effectiveness of the improvement of life skills to the children with ASD, and besides that, these researches should explore the interrelation between different therapies, highlighting its benefits.

\section{Disclosure statement}

The authors declare that there are no potential conflicts of interest.

\section{References}

1. Perera H, Jeewandara KC, Seneviratne S, Guruge C (2016) Outcome of home-based early intervention for autism in Sri Lanka: Follow-up of a cohort and comparison with a nonintervention group. BioMed research international.

2. Onzi FZ, De Figueiredo Gomes R (2015) Transtorno do Espectro Autista: a importância do diagnóstico e reabilitação. Revista Caderno Pedagógico $12(3)$.

3. Voss MSC, Schwartz J, Daniels J, Kline A, Haber N, et al. (2019) Effect of Wearable Digital Intervention for Improving Socialization in Children with Autism Spectrum Disorder. JAMA Pediatrics 173(5): 446-454.

4. García-Villamisar D, Dattilo J, Muela C (2017) Effects of therapeutic recreation on adults with ASD and ID: a preliminary randomized control trial. Journal of Intellectual Disability Research 61(4): 325-340.

5. Whitehouse AJO, Granich J, Alvares G, Busacca M, Cooper MN, et al (2017) A randomised controlled trial of an iPad-based application to complement early behavioural intervention in Autism Spectrum Disorder. Journal of Child Psychology and Psychiatry 58(9): 1042-1052.

6. Parsons D, Cordier R, Lee H, Falkmer T, Vaz S (2018) A Randomised Controlled Trial of an Information Communication Technology Delivered Intervention for Children with Autism Spectrum Disorder Living in Regional Australia. Journal of Autism and Developmental Disorders 49(2): 569-581.

7. Freitag CM, Jensen K, Elsuni L, Sachse M, Herpertz-Dahlmann B, et al (2016) Group-based cognitive behavioural psychotherapy for children and adolescents with ASD: the randomized, multicentre, controlled SOSTA-net trial. Journal of Child Psychology and Psychiatry 57(5): 596605.

8. Sehlin H (2018) Experiences of an Internet-Based Support and Coaching Model for Adolescents and Young Adults with ADHD and Autism Spectrum Disorder -A Qualitative Study. BMC Psychiatry 18(1): 15.

9. Shire SY, Chang YC, Shih W, Bracaglia S, Kodjoe M, et al. (2017) Hybrid implementation model of community-partnered early intervention for toddlers with autism: a randomized trial. Journal of Child Psychology and Psychiatry 58(5): 612-622.

10. Dawalt LS, Greenberg JS, Mailick MR (2018) Transitioning together: A multi-family group psychoeducation program for adolescents with ASD and their parents. Journal of autism and developmental disorders 48(1): 251-263.

11. Zhou B, Xu Q Li H, Zhang, Wang Y, et al. (2017) Effects of ParentImplemented Early Start Denver Model Intervention on Chinese Toddlers with Autism Spectrum Disorder: A Non-Randomized Controlled Trial. Autism Research 11(4): 655-666.

12. Ingersoll B, Wainer AL, Berger NI, Pickard KE, Bonter N (2016) Comparison of a Self-Directed and Therapist-Assisted Telehealth ParentMediated Intervention for Children with ASD: A Pilot RCT. Journal of Autism and Developmental Disorders 46(7): 2275-2284.

13. Steiner H, Kertesz Z (2015) Effects of therapeutic horse riding on gait cycle parameters and some aspects of behavior of children with autism. Acta Physiologica Hungarica 102(3): 324-335.

14. Choque Olsson N, Flygare O, Coco C, Görling A, Råde A, et al. (2017) Social Skills Training for Children and Adolescents with Autism Spectrum Disorder: A Randomized Controlled Trial. Journal of the American Academy of Child \& Adolescent Psychiatry 56(7): 585-592.

15. Begeer S, Patricia Howlin, Elske Hoddenbach, Cassandra Clauser, Ramon Lindauer, et. al. (2015) Effects and Moderators of a Short Theory of Mind Intervention for Children with Autism Spectrum Disorder: A Randomized Controlled Trial. Autism Research 8(6): 738-748.

16. Riquelme I, Hatem SM, Montoya P (2018) Reduction of Pain Sensitivity after Somatosensory Therapy in Children with Autism Spectrum Disorders. Journal of Abnormal Child Psychology 46(8): 1731-1740.

17. Bieleninik L, Geretsegger M, Mössler K, Assmus J, Thompson G, et al. (2017) Effects of Improvisational Music Therapy vs Enhanced Standard Care on Symptom Severity Among Children with Autism Spectrum Disorder. JAMA 318(6): 525-535.

18. Woo CC, Donnelly JH, Steinberg-Epstein R, Leon M (2015) Environmental Enrichment as a Therapy for Autism: A Clinical Trial Replication and Extension. Behavioral Neuroscience 129(4): 412-422.

19.Van Steensel FJA, Bögels SM (2015) CBT for Anxiety Disorders in Children with and Without Autism Spectrum Disorders. Journal Consulting Clinical Psychology 83(3): 512-523.

20. Vroland-Nordstrand K, Eliasson AC, Jacobsson $H$, Johansson $U$ Krumlinde-Sundholm L, et al. (2017) Can children identify and achieve goals for intervention? A randomized trial comparing two goal-setting approaches. Developmental Medicine \& Child Neurology 58(6): 589596.

21. Gengoux GW, Daniel A Abrams, Rachel Schuck, Maria Estefania Millan, Robin Libove, et al. (2019) A Pivotal Response Treatment Package for Children with Autism Spectrum Disorder: An RCT. American Academy of Pediatrics 144(3).

22. Geretsegger M, Holck U, Bieleninik $Ł$, Gold C (2016) Feasibility of a Trial on Improvisational Music Therapy for Children with Autism Spectrum Disorder. Journal of Music Therapy 53(2): 93-120. 
ISSN: 2574-1241

DOI: 10.26717/BJSTR.2020.27.004555

José Antônio Da Silva Neto. Biomed J Sci \& Tech Res

(c) (P) This work is licensed under Creative Commons Attribution 4.0 License

Submission Link: https://biomedres.us/submit-manuscript.php

\begin{tabular}{ll} 
BIOMEDICAL & Assets of Publishing with us \\
RESEARCHES & - Global archiving of articles \\
& - Immediate, unrestricted online access \\
\hline
\end{tabular}

